\title{
ANÁLISE FISIOLÓGICA EM MUDAS DE GUANANDI (Calophyllum brasiliense Cambess) SUBMETIDAS AO DÉFICIT HÍDRICO
}

\author{
Pedro Henrique Tavares de França ${ }^{1 *}$, Elaine Cristina Alves da Silva ${ }^{1}$, Thiago Cardoso Silva ${ }^{1}$, Nahila \\ Alves Brasil ${ }^{1}$, Rejane Jurema Mansur Custódio Nogueira ${ }^{1}$
}

\begin{abstract}
RESUMO: O guanandi (Calophyllum brasiliense Cambess) é uma espécie pertencente à família Clusiaceae, desenvolve-se preferencialmente em florestas semidecíduas, ombrófila densa, originária na região amazônica e do cerrado. Este trabalho teve por objetivo avaliar as respostas fisiológicas em plantas jovens de guanandi submetidas ao déficit hídrico. Foram utilizados 3 tratamentos hídricos: rega diária, rega a cada 5 dias e rega a cada 15 dias, com 5 repetições por tratamento, durante um período de 29 dias. Os parâmetros analisados foram: relações hídricas, trocas gasosas e pigmentos fotossintéticos. As mudas submetidas ao tratamento 15d SR atingiram um valor de -2,3 MPa para o potencial hídrico foliar e o teor relativo de água de $83 \%$, uma redução de $76 \%$ em sua fotossíntese e de $71 \%$ para a transpiração e um acréscimo em seu conteúdo de pigmentos fotossintéticos. As mudas de guanandi alteram seus processos fisiológicos com o objetivo de sobreviver sob condições de déficit hídrico.
\end{abstract}

Palavras-chave: seca, relações hídricas, trocas gasosas

\section{Physiological Analysis in Seedlings of Guanandi (Calophyllum brasiliense Cambess) Under a Water Deficit}

ABSTRACT: Guanandi (Calophyllum brasiliense Cambess) is a species of the Clusiaceae family, develops preferably in semi-deciduous forests, tropical rain, originating in the Amazon region and the Cerrado. This work aimed to evaluate the physiological responses in young plants guanandi submitted to drought. Three water treatments were used: daily watering, irrigation and irrigation every 5 days every 15 days, with 5 replicates per treatment over a period of 29 days. The parameters analyzed were: water relations, gas exchange and photosynthetic pigments. The seedlings subjected to treatment $15 \mathrm{~d}$ SR reached a value of $-2.3 \mathrm{MPa}$ for the leaf water potential and relative water content of $83 \%$, a reduction of $76 \%$ in their photosynthesis and $71 \%$ perspiration and an increase in content of photosynthetic pigments. The guanandi seedlings alter their physiological processes in order to survive under drought conditions.

Keywords: drought, water relations, gas exchang

\section{INTRODUÇÃO}

O guanandi (Calophyllum brasiliense Cambess) é uma espécie pertencente à família Clusiaceae, considerada climácica por apresentar regeneração abundante na sombra, ombrófila densa, originária da região amazônica e do cerrado, sendo encontrada em vários estados do Brasil, desenvolvendo-se preferencialmente em florestas semidecíduas (MARCONATO, 2010). A espécie tem crescimento adequado e normal em qualquer bacia brasileira, porém apresenta características de adaptação a variados climas e solos, desde inférteis e secos, até encharcados e brejosos, fato que ao coloca à frente de outras quando em condições de competição e possui resistência à herbivoria provocada por insetos (LISBOA et al., 2012).

Seu crescimento é monopodial, característica que proporciona fustes bem definidos, podendo chegar a $40 \mathrm{~m}$ de altura e $1,5 \mathrm{~m}$ de diâmetro, e seu ponto de corte adequado é com cerca de 20 anos
(CARVALHO, 1994). Considerada a primeira Madeira de Lei do Brasil desde o ano de 1835, essa espécie apresenta características estéticas com potencial para substituir o mogno (Swietenia macrophylla King) e o cedro (Cedrela fissilis Vell.), podendo ser utilizada para fabricação de móveis finos, nas construções naval e civil, chapas, lâminas faqueadas, fabricação de barris de vinho etc. (NERY et al., 2007; LISBOA et al., 2012).

É importante o desenvolvimento de estudos que visem à ampliação da produção de guanandi na região Nordeste, a qual é caracterizada por apresentar baixa disponibilidade hídrica. Esta apresenta fatores climáticos que não se restringem às áreas semiáridas, uma vez que mesmo em regiões consideradas úmidas, a irregularidade na distribuição das chuvas e tal condição podem, de acordo com Taiz \& Zeiger (2009), limitar o crescimento das plantas. Essa situação adversa não 
pode ser amenizada, a não ser com projetos de irrigação, o que torna inviável o cultivo de muitas espécies. Quando a planta é submetida a condições de reduzida disponibilidade hídrica, algumas de suas funções vitais podem ser comprometidas e, para sobreviver, respostas adaptativas são desencadeadas, de forma que a mesma possa resistir a longos períodos de seca (PINZÓN-TORRES; SCHIAVINATO, 2008).

$\mathrm{O}$ teor de água nos tecidos vegetais varia de acordo com as condições ambientais e a água é de importância vital, sendo um dos fatores determinantes para a diversidade e distribuição das plantas. Estudos que abordem o status hídrico em guanandi são válidos para enriquecer e proporcionar o manejo adequado desta espécie em condições adversas, principalmente voltado às condições edafoclimáticas da região Nordeste do Brasil (NASCIMENTO, 2009). A deficiência hídrica afeta os diversos processos fisiológicos, aumentando a resistência dos estômatos à difusão do vapor de água, reduzindo assim a transpiração e consequentemente o suprimento de $\mathrm{CO}_{2}$ para a fotossíntese (NOGUEIRA; SANTOS, 2000). Para fins de evitar o dessecamento excessivo, as plantas realizam o fechamento estomático, que é considerada a primeira linha de defesa, mesmo antes de ocorrer a diminuição do conteúdo da água da folha (LARCHER, 2000). Algumas substâncias agem como sinalizadores do estresse e períodos de déficit hídrico induzem a síntese de ácido abscísico nas raízes que é transportado para a parte aérea através do xilema, provocando o fechamento dos estômatos (TAIZ; ZEIGER, 2009). Os efeitos do estresse hídrico nos pigmentos vegetais (as clorofilas e os carotenoides) podem resultar em distúrbios no balanço osmótico, como a perda de turgescência e diminuição do crescimento, podendo levar à degradação da clorofila, pigmento necessário para a realização da fotossíntese (MARQUES, 2011).

Diante do exposto, este trabalho tem por escopo avaliar as relações hídricas e as trocas gasosas, além de determinar a concentração de pigmentos fotossintéticos em razão do estresse hídrico em plantas juvenis da espécie Calophyllum brasilienses Cambess.

\section{MATERIAIS E MÉTODOS}

$\mathrm{O}$ experimento foi conduzido em casa de vegetação do Laboratório de Fisiologia Vegetal da Universidade Federal Rural de Pernambuco, no período de 29 dias, no qual se utilizaram mudas, propagadas por sementes coletadas no município de Paudalho.

$\mathrm{O}$ delineamento experimental utilizado foi inteiramente casualizado, em regime de ciclo de rega, os tratamentos empregados foram rega diária
(RD), rega a cada 5 dias (5d SR) e rega a cada 15 dias (15d SR), com 5 repetições por tratamento, totalizando 15 parcelas. As plantas do tratamento $5 \mathrm{~d}$ SR receberam 5 irrigações, enquanto as plantas do tratamento 15d SR receberam apenas uma. Após 29 dias de imposição ao estresse procedeu-se a realização das avaliações fisiológicas: Trocas gasosas, relações hídricas e pigmentos fotossintéticos.

As trocas gasosas foram realizadas às 11 horas da manhã, considerado o horário de maior demanda evaporativa para a maioria das espécies. Esta análise foi realizada nas folhas localizadas no terço médio superior das plantas, utilizando o analisador portátil de $\mathrm{CO}_{2}$ a infravermelho - IRGA (LCpro+ADC). As variáveis avaliadas foram: fotossíntese (A), transpiração (E), e condutância estomática (gs). De posse dos valores de A e E, foi calculada a eficiência instantânea do uso da água (EiUA), pela relação A/E.

Folhas do terço médio superior foram coletadas, rapidamente envoltas em filme plástico e em seguida acondicionadas em caixa de isopor refrigerada para posterior determinação do potencial hídrico foliar (Yf) na câmara de pressão (SCHOLANDER et al., 1965), em laboratório. O teor relativo de água (TRA) foi determinado, utilizando-se seis discos de área conhecida da matéria fresca (desprezando-se as nervuras), os quais foram imediatamente pesados para obtenção do peso da massa fresca (PMF). Em seguida, os mesmos foram acondicionados em placas de Petri, com papel filtro, contendo $10 \mathrm{~mL}$ de água destilada e acondicionadas em refrigerador por um período de 24 horas. Após esse período, os discos foram novamente pesados para obtenção do peso da massa túrgida (PMT). Finalmente, os discos foram colocados em estufa com circulação forçada de ar a $65^{\circ} \mathrm{C}$, até atingirem peso constante, obtendose assim o peso da massa seca (PMS). O TRA foi calculado através da fórmula: TRA $=\{[(\mathrm{PMF}-$ PMS) / (PMT - PMS)] x 100\}, conforme citado por Weatherley (1950).

A avaliação dos pigmentos fotossintéticos foi realizada segundo a metodologia de Lichtenthaler e Buschmann (2001), coletando-se 0,1 g do limbo foliar que, após serem recortados, foram vertidos para tubos de ensaio rosqueáveis, previamente revestidos com papel alumínio contendo acetona a $80 \%$ para extração dos pigmentos. Após 24 horas, realizaram-se as leituras em espectrofotômetro BIOspectro modelo SP-200, nos comprimentos de onda $664 \mathrm{~nm}, 647 \mathrm{~nm}$ e $470 \mathrm{~nm}$ para determinação da clorofila $a, b$ e carotenoides, e com a soma das concentrações das clorofilas $a$ e $b$, calculou-se a clorofila total.

Os resultados foram submetidos à análise de variância usando o software Assistat beta 7.2 e as 
médias comparadas entre si pelo teste de Tukey ao nível de $5 \%$ de probabilidade.

\section{RESULTADOS E DISCUSSÕES}

$\mathrm{Na}$ figura 1 percebe-se que as plantas de guanandi reduziram significativamente seu potencial hídrico foliar nas plantas com o déficit hídrico, onde as plantas submetidas ao tratamento de $5 \mathrm{~d}$ SR apresentaram uma redução de $53 \%$ e as plantas do tratamento $15 \mathrm{~d}$ SR uma redução de $155 \%$, em comparação com as plantas que receberam a rega diária (Figura 1A). A variável TRA também foi afetada significativamente nas plantas submetidas à deficiência hídrica, em relação às plantas do tratamento rega diária, as quais apresentaram um valor médio de $86 \%$ (Figura 1B), comparado aos tratamentos de $5 \mathrm{~d}$ SR e $15 \mathrm{~d}$ SR, com médias de $82 \%$ e $83 \%$, respectivamente.

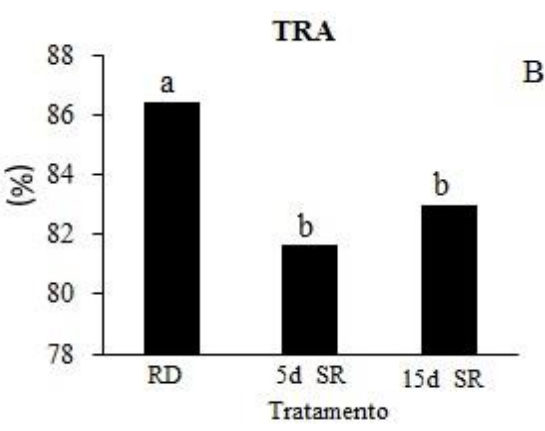

Figura 1. Potencial hídrico foliar (A) e TRA (B) em mudas de guanandi cultivados em casa de vegetação submetida a diferentes regimes hídricos. Médias seguidas por mesma letra não diferem entre si pelo teste de Tukey a 5\% de probabilidade.

Corroborando com o presente trabalho, Albuquerque et al. (2013) trabalhando com o mogno africano (Khaya ivorensis A. Chev), nas mesmas condições desse trabalho, verificaram valores de potencial hídrico foliar baixo $(-2,66 \mathrm{MPa})$. Além disso, esses autores constataram que o teor relativo de água sofreu uma redução na ordem de $62 \%$, nas plantas sob déficit hídrico.

$\mathrm{O}$ movimento da água se dá pelo gradiente de potencial, e para que haja o fluxo de água, o potencial hídrico do solo deve estar maior que o da planta. No entanto, sob déficit hídrico, aquele é reduzido e para que as raízes absorvam a água, as plantas reduzem o seu potencial hídrico para continuar a absorção, este mecanismo foi observado em Jatropha curcas (MOURA et al., 2016). Esta redução pode ser atribuída ao ajuste osmótico devido ao acúmulo de solutos orgânicos de baixo peso molecular, como foi observado em Hymenaea courbaril (NASCIMENTO et al., 2015). Para ter certeza desse mecanismo de defesa seria necessária a análise de variáveis bioquímicas (proteína, carboidratos, aminoácidos), no intuito de determinar a concentração dos osmóticos compatíveis, responsáveis por tal ajustamento (NOGUEIRA; SILVA, 2005).

As plantas submetidas à restrição hídrica sofreram reduções significativas nas variáveis fotossíntese, transpiração e condutância estomática (Figuras 2A, 2B e 2D), mas não na eficiência do uso da água (Figura 2C). De acordo com os resultados, a fotossíntese foi reduzida em $66 \%$ e $77 \%$ nos tratamentos $5 \mathrm{~d}$ SR e $15 \mathrm{~d}$ SR, respectivamente, em relação ao tratamento de rega diária (Figura 2A). Com relação à transpiração, essa foi reduzida drasticamente após 5d SR (78\%) e nas plantas após $15 \mathrm{~d}$ SR, a redução foi na ordem de $71 \%$ (Figura $2 \mathrm{~B}$ ). Semelhante às variáveis anteriores, a condutância estomática também foi reduzida nas plantas submetidas à seca, apresentando média de 0,03 mol. $\mathrm{H}_{2} \mathrm{O} . \mathrm{m}^{-2} \mathrm{~s}^{-1}$ dos tratamentos $5 \mathrm{~d} \mathrm{RD}$ e $15 \mathrm{~d} \mathrm{RD}$, comparada com as plantas do tratamento de rega diária, que foi de $0,18 \mathrm{~mol} \cdot \mathrm{H}_{2} \mathrm{O} \mathrm{m}^{-2} \mathrm{~s}^{-1}$ (Figura 2C). Já a eficiencia instantânea do uso da água foi semelhante em todos os tratamentos avaliados (Figura 2D). 

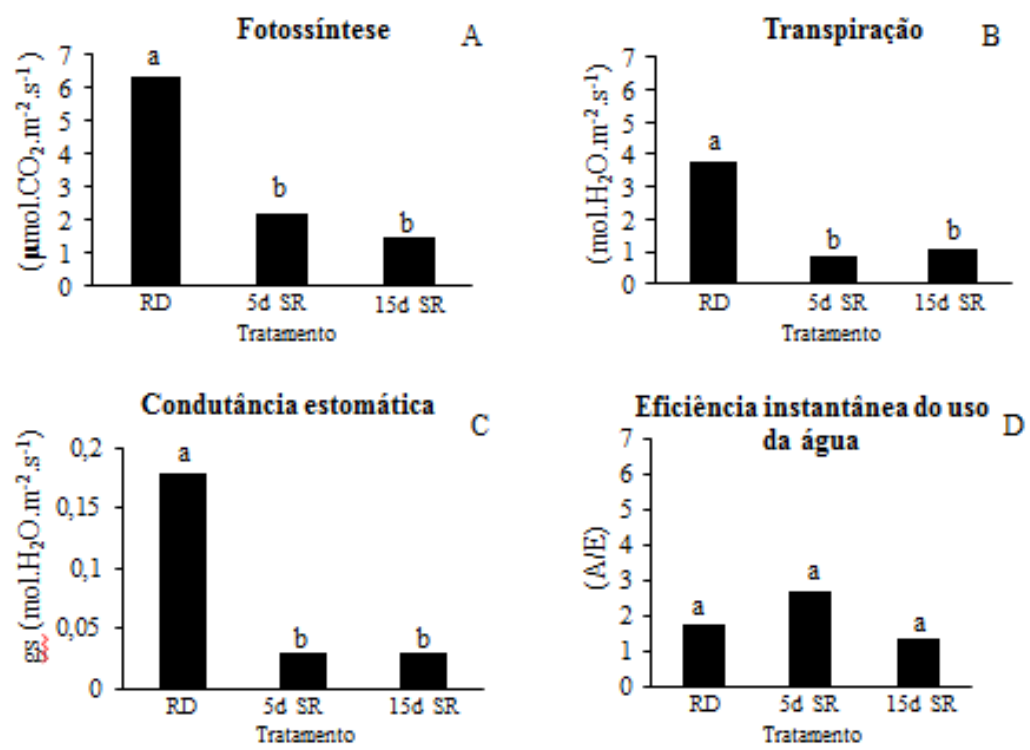

Figura 2. Fotossíntese (A), transpiração (B), condutância estomática (C) e eficiência instantânea do uso da água (D) em mudas de guanandi submetidas a diferentes ciclos de rega. Médias seguidas por mesma letra não diferem entre si pelo teste de Tukey a 5\% de probabilidade.

Os resultados de troca gasosas corroboram com os obtidos por Tatagiba et al. (2007) em clones de eucaliptos, e Costa et al. (2015) em plantas de aroeira, em que foram constatadas reduções das taxas de fotossíntese, transpiração e a condutância estomática quando submetidas ao estresse hídrico.

A baixa disponibilidade hídrica, conforme observada nos resultados do presente trabalho, afetaram os diversos processos fisiológicos, tais como a transpiração, a condutância dos estômatos e consequentemente o suprimento de $\mathrm{CO}_{2}$ para a realização da fotossíntese (NOGUEIRA; SANTOS, 2000). Segundo Inman-Bamber e Smith (2005), as plantas têm que contrabalançar a necessidade de guardar água e assimilar $\mathrm{CO}_{2}$, fazendo com que a área foliar exerça papel importante na difusão do dióxido de carbono e no vapor d'água através dos estômatos.

Conforme Larcher (2000), o estresse hídrico afeta, primeiramente, o aparelho estomático, provocando o seu fechamento, e essa teoria é confirmada por Silva et al. (2008) no qual utilizaram plantas jovens de Schinus terebinthifolius Raddi e verificaram o fechamento dos estômatos nas plantas que passaram por ciclos de rega. O fechamento estomático é um mecanismo utilizado pelas plantas para evitar que a pouca água absorvida não seja perdida na transpiração, uma vez que a manutenção da água no interior das células é importante para a realização das reações metabólicas (ALBUQUERQUE et al., 2013). De acordo com o presente trabalho, pode-se afirmar que as plantas de guanandi podem ter utilizado como a primeira linha de defesa o fechamento dos estômatos contra o déficit hídrico, no qual foi constatado nos ciclos de rega a cada 5 e 15 dias, este mecanismo permitiu as plantas a utilizarem de forma eficiente a água que foi absorvida.

Com relação aos teores de clorofila $a$ e carotenoide, pode-se observar que não foram alterados com o estresse hídrico (Figura 3A e 3D). Diferentemente, ocorreu para a clorofila $b$, em que os maiores valores foram encontrados nas plantas mantidas a $5 \mathrm{~d}$ SR $(1,1 \mathrm{mg} / \mathrm{g}$ MF) e $15 \mathrm{~d}$ SR $(1,2 \mathrm{mg} / \mathrm{g}$ MF), ambas diferindo estatisticamente das plantas do tratamento controle $(0,73 \mathrm{mg} / \mathrm{g} \mathrm{MF})$ (Figura 3B). A clorofila total das plantas submetidas ao estresse $5 \mathrm{~d}$ SR e 15d SR foi de 1,6 e 1,8 mg/g MF, respectivamente, em relação as plantas do ciclo de rega diária (Figura 3C). 
Clorofila a

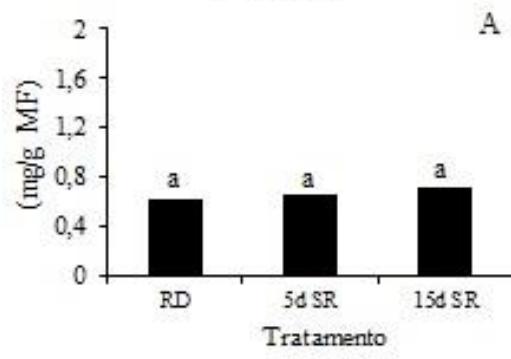

Clorofila Total

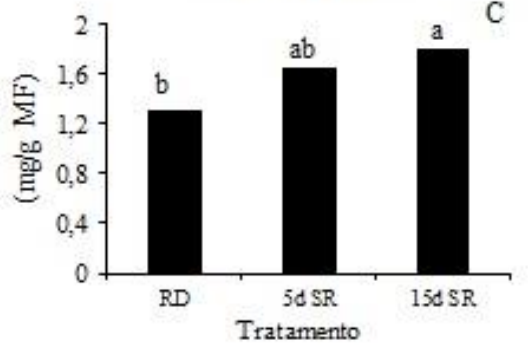

Clorofila b
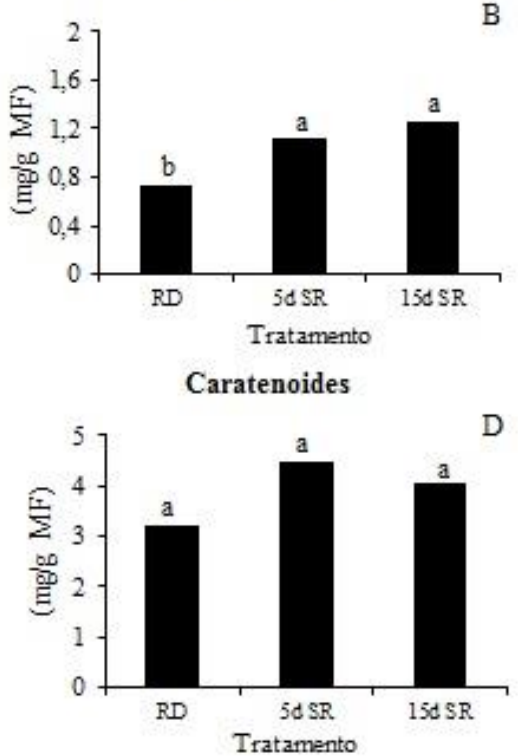

Figura 3. Teores de clorofila $a(\mathrm{~A})$, clorofila $b(\mathrm{~B})$, clorofila total $(\mathrm{C})$ e carotenoides $(\mathrm{D})$ em mudas de guanandi submetido à deficiência hídrica. As médias seguidas por mesma letra minúsculas para os tratamentos salinos, não diferem entre si pelo teste de Tukey probabilidade

Segundo Luís (2009) o teor de clorofila poderá sofrer maior ou menor degradação dependendo do nível de estresse. Nautiyal et al. (1996), trabalhando com Pongamia pinnata (L.), sugeriram que as plantas foram capazes de sobreviver e manter-se fotossinteticamente ativas em condições moderadas de déficit hídrico de até 30 dias sem rega, aumentando os teores dos pigmentos fotossintéticos. Segundo Marques (2011), a planta produz carotenoide e a clorofila $b$ sob condições de estresse, pois são pigmentos fotoprotetores, e previnem à foto-oxidação da clorofila $a$ no processo da fotossíntese, e isto foi confirmado na presente pesquisa com a clorofila $b$.

\section{CONCLUSÕES}

Sob déficit hídrico, mudas de guanandi diminuem o potencial hídrico foliar, regulam a abertura estomática, reduzindo sua fotossíntese e transpiração e investem na produção de clorofila $b$.

\section{REFERÊNCIAS}

ALBUQUERQUE, M. P. F.; MORAES, F. K. C.; SANTOS, R. I. N.; CASTRO, G. L. S.; RAMOS, E. M. L. S.; PINHEIRO, H. A. Ecofisiologia de plantas jovens de mogno-africano submetidas a déficit hídrico e reidratação. Pesquisa Agropecuária brasileira, Brasília, v. 48, n. 1, p. 9-16, 2013. doi: http://dx.doi.org/10.1590/S0100204 X2013000100002

CAIRO, P. A. R. Curso básico de relações hídricas de plantas. Vitória da Conquista: UESB, 1995. 32p.
CARVALHO P. E. R. Espécies florestais brasileiras. Recomendações silviculturais, potencialidades e uso da madeira. Colombo: Embrapa-CNPF/Brasília: Embrapa-SPI, 1994. 640p.

COSTA, A. S.; FREIRE, A. L. O.; BAKKE, I. A.; PEREIRA, F. H. F. Respostas fisiológicas e bioquímicas de plantas de aroeira (Myracrodruon urundeuva Allemão) ao déficit hídrico e posterior recuperação. Irriga, Botucatu, v. 20, n. 4, p. 705717, 2015.

doi:

http://dx.doi.org/10.15809/irriga.2015v20n4p705

INMAN-BAMBER, N. G.; SMITH, D. M. Water relation in sugarcane and response to water deficits. Field Crops Research, v. 92, n. 14, p. 185-202, 2005. doi: https://doi.org/10.1016/j.fcr.2005.01.023

LARCHER, W. Ecofisiologia vegetal. São Carlos: RiMa, 2000. 531p.

LISBOA, A. C.; SANTOS, P. S.; OLIVEIRA NETO, S. N.; CASTRO, D. N.; ABREU, A. H. M.. Efeito do volume de tubetes na produção de mudas de Calophyllum brasiliense e Toona ciliata. Revista Árvore, Viçosa, v. 36, n. 4, 2012. doi: http://dx.doi.org/10.1590/S0100-

67622012000400003

LUÍS, R. M. F. C. B. Respostas de Jatropha curcas L. ao déficit hídrico: caracterização bioquímica e ecofisiológica. 2009. 62f. Dissertação (Mestrado em Engenharia Agronómica) - Instituto Superior de 
Agronomia, UTL - Universidade Técnica de Lisboa, Lisboa, 2009.

MARCONATO, G. Degradação do bioma floresta atlântica - matas ciliares - e a necessidade do desenvolvimento de métodos para a sua restauração no estado de São Paulo. 2010. 129f. Dissertação (Mestrado em Ciências Florestais) Instituto de Biociências, UNESP - Universidade Estadual Paulista, Botucatu, 2010.

MARQUES, M. C. Toxicidade por metais pesados em pinhão-manso e mamona cultivados em solução nutritiva. 2013. 177f. Tese (Doutorado em Ciência do Solo) - Universidade Federal Rural de Pernambuco, Recife, 2013.

MARQUES, R. P.; FREIRE, C. S.; NASCIMENTO, H. H. C.; NOGUEIRA, R. J. M. C. Relações hídricas e produção de pigmentos fotossintéticos em mudas de Eugenia uniflora L. sob condições de salinidade. Revista Brasileira de Geografia Física, Recife, v. 4, n. 3, p. 497-509, 2011.

MOURA, A. R.; NOGUEIRA, R. J. M. C.; SILVA, J. A. A.; LIMA, T. V. Relações hídricas e solutos orgânicos em plantas jovens de Jatropha curcas 1 . sob diferentes regimes hídricos. Ciência Florestal, Santa Maria, v. 26, n. 2, p. $345-354,2016$. doi: http://dx.doi.org/10.5902/1980509822735

NASCIMENTO, H. H. C. Caracterização ecofisiológica de mudas de jatobá (Hymenaea courbaril L.) submetidas a déficit hídrico. 2009. 91f. Dissertação (Mestrado em Ciências Florestais) Universidade Federal Rural de Pernambuco, Recife, 2009.

NASCIMENTO, H. H. C.; SANTOS, C. A.; FREIRE, C. S.; SILVA, M. A.; NOGUEIRA, R. J. M. C. Ajustamento osmótico em mudas de jatobá submetidas à salinidade em meio hidropônico. Revista Árvore, Viçosa, v. 39, n. 4, p. 641-653, $2015 . \quad$ doi :http://dx.doi.org/10.1590/010067622015000400006 .

NAUTIYAL, S.; NEGI, D. S.; KUMAR, S. Effect of water stress and antitranspirants on the chlorophyll contents of the leaves of Pongamia pinnata (L.) Pierre. The Indian Forester, v. 122, n. 11, p. 10181022, 1996.

NERY, F. C.; ALVARENGA, A. A.; JUSTO, C. F.; CASTRO, E. M.; SOUZA, G. S.; ALVES, E. Aspectos anatômicos de folhas de plantas jovens de Calophyllum brasiliense Cambess submetidas a diferentes níveis de sombreamento. Revista
Brasileira de Biociências, Porto Alegre, v. 5, supl. 2, p. 129-131, 2007.

NOGUEIRA, R. J. M. C.; SANTOS, R. C. Alterações fisiológicas no amendoim, submetido ao estresse hídrico. Revista Brasileira de Engenharia Agrícola e Ambiental, Campina Grande, v. 4, n. 1, p. 41-45, 2000.doi: http://dx.doi.org/10.1590/S1415$\underline{43662000000100008}$

NOGUEIRA, R. J. M. C.; SILVA, E. C. Aspectos Ecofisiológicos da tolerância à seca em plantas da Caatinga. In: NOGUEIRA, R. J. M. C.; ARAÚJO, E. L.; WILLADINO, L. G.; CAVALCANTE, U. M. T. (Org.). Estresses Ambientais: danos e benefícios em plantas. $1^{a}$ ed. Recife: MXM Gráfica e Editora, 2005. 22-31p.

PINZÓN-TORRES, J. A.; SCHIAVINATO, M. A. Crescimento, eficiência fotossintética e eficiência do uso da água em quatro espécies de leguminosas arbóreas tropicais. Hoehnea, v. 35, n. 3, p. 395-404, 2008.

SHABALA, S. Metal cations in $\mathrm{CO}_{2}$ assimilation and conversion by plants. Journal of the Minerals, Metals and Materials Society, v. 61, n. 4, p. 28-34, 2009.

SILVA, M. A. V.; NOGUEIRA, R. J. M. C.; OLIVEIRA, A. F. M.; SANTOS, V. F. Resposta estomática e produção de matéria seca em plantas jovens de aroeira submetidas a diferentes regimes hídricos. Revista Árvore, Viçosa, v. 32, n. 2, p. 335-344, 2008. doi:

http://dx.doi.org/10.1590/S0100$\underline{67622008000200016}$

TAIZ, L; ZEIGER, E. Fisiologia vegetal. 4. ed. São Paulo: Artmed, 2009. 848p.

TATAGIBA, S. D.; PEZZOPANE, J. E. M.; REIS, E. F. Relações hídricas e trocas gasosas na seleção precoce de clones de eucalipto para ambientes com diferenciada disponibilidade de água no solo. Floresta, Curitiba v. 3 8, n. 2, p. 387-400, 2008. doi: http://dx.doi.org/10.5380/rf.v38i2.11633

WEATHERLEY, P. E. Studies in the water relations of cotton plant. I. The field measurements of water deficits in leaves. New Phytologist, v. 49, p. 81-97, 1950. 